\title{
Energy Efficiency and Grid Flexibility through Building to Vehicle to Buildings Approach: Modelling and Simulation
}

\author{
Giovanni Barone ${ }^{1}$, Annamaria Buonomano ${ }^{1,2}$, Cesare Forzano ${ }^{3}$, Gaetano Galano ${ }^{1}$, Adolfo Palombo ${ }^{1}$ \\ ${ }^{1}$ Dept. of Industrial Engineering, University of Naples Federico II, Naples, Italy \\ ${ }^{2}$ Dept. of Building, Civil and Environmental Engineering, Concordia University, Montreal, Canada \\ ${ }^{3}$ Faculty of Science and Technology, Free University of Bozen, Bolzano, Italy
}

\begin{abstract}
This paper focuses on a novel energy management approach, namely Building to Vehicle to Building $\left(\mathrm{V} 2 \mathrm{~B}^{2}\right)$, conceived for cluster of buildings connected in micro-grids, by considering electric vehicles as vector devices for renewable energy exchanges. The main goal behind this concept is to benefit from the potentiality of electric vehicles toward the achievement of the zeroenergy target, extended to the buildings of a virtual microgrid, by exploiting off-site the PV generation. To this aim, a dynamic simulation model is suitably developed for the building energy demands and loads assessment, taking also into account the vehicles energy use. PV electricity is stored in the vehicle batteries and dispatched to other buildings or, at last, to the power grid.

In order to show the advantages of the proposed concept and the potentials of the developed simulation tool, implemented in TRNSYS, a suitable case study is conducted. It refers to a non-residential net zero energy building where PV panels are installed for renewable energy production, also supplied to three electric vehicles. These also acts as energy vectors providing stored electricity to two other buildings, where off-site renewable energy is exploited. At the micro-grid level, the match between renewable generation and system demand (buildings and electric vehicles' needs) is enhanced, reducing the grid operation and boosting the system economic convenience.
\end{abstract}

\section{Introduction}

Recent international directives require lower building energy consumption and reduced pollutant emissions of cities. In this regard, Electric Vehicles (EVs) are considered key devices to reach this target. Their storage capacity could be exploited, besides electric motion needs, for the renewable energy transfer from one building to another. Such novel building energy management approach is namely Building to Vehicle to Building $\left(V_{2} B^{2}\right)$. In this way, the NZEB goal can be achieved also by buildings that for some reason cannot be refurbished (economic or architectonic constraints, etc.). Such EVs can be also used for electricity dispatchment to the electricity power grid. At this moment, literature papers on this topic appear still rather rare. Besides the first work on V2B ${ }^{2}$ (Barone et al., 2019), few studies were conducted (De Angelis F. et al., 2013; Kuang Y. et al., 2017; Salpakari J. et al., 2017).
In order to assess the energy saving and the economic convenience of the microgrid obtained through this novel approach, suitable calculation tools were developed by the authors. A comprehensive tool was developed in MatLab, with the aim to investigate the energy and economic performance of microgrids consisting of a house and an office building connected by an EV (featuring a basic nucleus based on human activities). The $\mathrm{EV}$ acts as transfer vector for the electricity produced by tilted roof or vertical façade PV panels alternatively installed on one building (Barone et al., 2019). Results obtained for the case study, characterized by shifted electricity production (from renewable energy sources, RES) and demand, showed interesting energy and economic savings with respect to a traditional system (without PV): the grid electricity consumption was remarkably reduced up to 45 and $77 \%$ as a function of the simulated V2B ${ }^{2}$ scenarios.

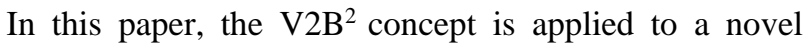
analysis, carried out to assess the energy and economic performance of a virtual micro-grid consisting of multiple users which require electricity simultaneously to the PV production. Specifically, the study refers to a cluster of three buildings (one of them equipped by BIPV panels) connected through three EVs. Here, the V2B ${ }^{2}$ scheme (buildings, PV panels, electric vehicles, and energy storage systems) are suitably modelled in TRNSYS. Bidirectional electricity exchanges among the grid, as well as buildings and mobility consumptions are dynamically simulated. Energy and economic indexes are calculated to assess the system effectiveness for the weather zone of Naples (Italy). Results show that the grid electricity consumption is significantly reduced, and the match between demand and production is enhanced.

\section{System description}

In the framework of the proposed $\mathrm{V}^{2} \mathrm{~B}^{2}$ concept, the $\mathrm{EV}$ acts as energy user, storage and vector, with the aim of contributing to the achievement of the net or nearly zero energy target at a micro-grid level. The EV stores renewable electricity and transfer it from one building to other ones. The system efficiency depends on the efficiency of installed RESs as well as on EV motion and final building demands. In this paper, the investigated micro-grid layout, shown Figure 1, consists of:

- three office users: one office building (namely Main building) where a RES system is installed and two office spaces (namely Satellite buildings). Here, 
electric HVAC systems and appliances are installed;

- Building Integrated PhotoVoltaic (BIPV) panels on the tilted roof of the Main building. The PV system supplies electricity to all offices users (i.e. heating, cooling, equipment, lights) and to the EVs;

- three EVs which alternatively reach the three considered buildings, rotating among them as a function of their daily routes, charging or discharging their batteries (EVB) depending on the micro-grid needs (bidirectional operation).

In the following, the system logic of the proposed V2B scheme is described in order to show how PV production and users (offices and EVs) demands/supply are managed for maximizing the self-consumption of RES within the micro-grid (reducing the energy provided from and delivered to the grid, namely Grid (Damiano A. et al., 2014)). Energy fluxes interact among the delivery and consumption points according to the occurring energy needs and EVB storage capacities (State Of Charge, SOC), and their maximum and minimum safety levels. The instantaneous power demands of the three users are satisfied by the PV generation produced on site at the Main building and dispatched by the EVs, whereas power is drawn by the EVBs due to their motion needs and users' demands, while the Grid supplies the residual energy demand. The three vehicles, rotating among the users, have different daily schedules, planned to simulate the personnel commuting route from the Main building to the Satellite ones. When an EV reaches a building and it is plugged to its building management system (BMS), it acts as an electricity source (necessary to cover the electrical user needs) until its capacity reaches the minimum SOC level. Similarly, when an EV is connected to the BMS of the Main building, the surplus of PV generation (i.e. higher than the Main building electrical needs, which is so fully balanced by renewable energy) is either stored into the EVBs, until their maximum SOC levels are reached, or fed into the Grid. Note that, the three EVBs are charged with the surplus of renewable electricity starting from the fullest to the emptiest one (priority charging order).

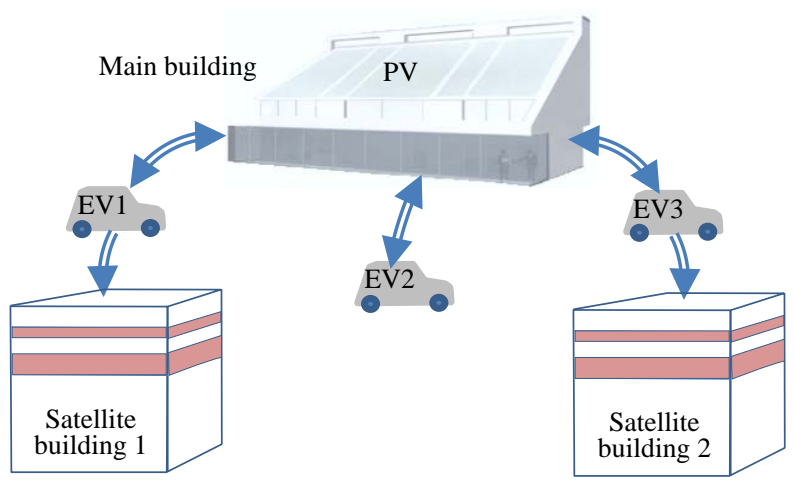

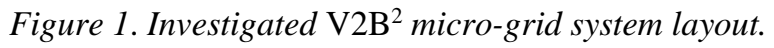

\section{Modelling}

A short description of the implemented TRNSYS (Klein S.A. et al., 2006) model developed for dynamically simulating the ${\mathrm{V} 2 \mathrm{~B}^{2}}^{2}$ system layout is reported. The simulation model is based on several components as well as other necessary devices (e.g. heat pumps, chillers, controllers, diverters, mixers, pumps, etc.). For the sake of brevity, only the Main components linked to the V2B ${ }^{2}$ system behaviour are described hereinafter.

\section{Building model}

Heating and cooling demands and electrical loads of each building user are calculated through a transient simulation tool, where building envelope features, ventilation rates and internal gains (thermal and electrical) are detailly set. The two investigated building typologies, including all energy plants, are differently modelled. Specifically:

- Main building: the user demand is dynamically assessed by Type 56. The building tri-dimensional geometric model is obtained by means of the plug-in Google SketchUp TRNSYS3d;

- Satellite buildings: the user demand is previously calculated by means of an in-house building simulation tool (Barone et al., 2019), and entered as an external input to the TRNSYS model.

For each building, indoor air temperature set points are obtained through an electric heat pump/chiller.

\section{BIPV system}

Building Integrated PV (BIPV) panels are modelled by the TRNSYS Type 567. The panels are embedded into the Main building roof to produce electricity, firstly used for balancing its demand. Produced electricity surplus is then exploited for charging the EVs batteries and, at last, for feeding the Grid.

\section{EV model}

Each EV battery (EVB) and inverter are modelled by the TRNSYS Type 47b and 48c, respectively. Type 47 parameters are suitably modified in order to model a lithium-ion battery which features the EVB behaviour of a commercially available EV. Note that, the EV electricity consumption depends on the driving speed (TeslaMotors, 2017), according to motion patterns. Type 48 simulates the regulator/inverter, which converts DC (produced by $\mathrm{PV}$ ) into AC (for building devices and EVs).

\section{Case study}

In the Proposed V2B ${ }^{2}$ System (PS) layout, EVs are also used as electricity vectors, to dispatch PV electricity from the Main building to the Satellite ones, as sketched in Figure 1. PS is compared to a typical V2B scenario, namely Reference System (RS), where the EVs exchange electricity with the Main building only. Both layouts are based on a virtual micro-grid including three office users and three EVs, by considering bidirectional operation of each EVB, which, according to the SOC level, is:

i. charged at the Main building (by PV panels and Grid);

ii. discharged at the Main and Satellite buildings for the PS case, and at the Main building only for the RS case. 
The Main building is based on a non-residential NZEB, designed for the Mediterranean climate of Naples (South Italy). It includes offices, conference, and exposition spaces. The building air-conditioned surface area is about $300 \mathrm{~m}^{2}$. PV panels are integrated into the building tilted roof. Simulation assumptions relative to building design and operating parameters are detailly reported in (Buonomano A., 2020).

Satellite buildings are two twin offices (namely, Sat A and Sat B), each one of about $200 \mathrm{~m}^{2}$ of surface area. They refer to a single intermediate floor office spaces of a multi-floor building, simulated as a South facing perimeter thermal zone. Such buildings are ideally located in two different zones of the city, with the aim to simulate different EVs routes. All assumptions of these users are reported in (Barone et al., 2019).

Main and Satellite buildings have the same heating and cooling schedules and temperature set points, as well as occupancy and HVAC schedules (Table 1). In particular, the HVAC system is activated from 08:00 to 17:30, from November $15^{\text {th }}$ to March $31^{\text {st }}$ and from June $1^{\text {st }}$ to September $30^{\text {th }}$. Heating and cooling electricity demands are based on the heat pump/chiller coefficients of performance, calculated as a function of the occurring operating conditions and part-load ratio, $\mathrm{f}_{\mathrm{PLR}}$ [46].

Table 1. Buildings operating assumptions.

\begin{tabular}{|l|c|}
\hline \multicolumn{1}{|c|}{ Parameter } & Value \\
\hline $\begin{array}{l}\text { Occupancy, appliances, and } \\
\text { HVAC schedules [hours] }\end{array}$ & $8: 00-17: 30$ \\
\hline Heating set-point [ $\left.{ }^{\circ} \mathrm{C}\right]$ & 20 \\
\hline Cooling set-point [ $\left.{ }^{\circ} \mathrm{C}\right]$ & 26 \\
\hline Heating period [month/day] & $11 / 15^{\text {th }}-3 / 31^{\text {st }}$ \\
\hline Cooling period [month/day] & $6 / 01^{\text {st }}-9 / 30^{\text {th }}$ \\
\hline Week opening [-] & Mon-Sat \\
\hline
\end{tabular}

Each electric vehicle is considered as used by the Main building personnel for commuting among workplace buildings. In this regard, it is intended that the Main building is considered as located in the outskirt of the city, whereas Sat A and Sat B buildings are in the city centre. The three EVs driving distances, covered from the Main building to Sat A and to Sat B, are modelled by following such daily routes, namely:

- Main building daily stay: the EV with the lowest SOC level at early morning remains at the Main building to be charged by PV panels during the day (if surplus is available). The vehicle leaves for two short trips, the first is scheduled between 9:00 am and 9:40 am, the second between 11:30 am and 12:10 pm (EV velocity ranging from 30 to $50 \mathrm{~km} / \mathrm{h}$ );

- Main building morning stay: the EV with the second highest SOC level at early morning is scheduled to stay connected to the Main building during morning, then at 1:00 pm it leaves the building to reach one of the two satellite building (either Sat A or Sat B) where it can supply stored renewable electricity to the user (discharging mode, if sufficient stored electricity is available) from 2:00 pm to $5: 30 \mathrm{pm}$, returning to the Main building at 6:30 pm. EV velocity during the two equal trips ranges from 50 to $60 \mathrm{~km} / \mathrm{h}$;

- Main building leave: the EV with the highest SOC level at early morning is scheduled to leave the Main building at 8:30 am (reaching the Satellite one at 9.20 $\mathrm{am}$ ) and to return at 6:20 pm (leaving the Satellite one at $5.30 \mathrm{pm}$ ). During the time in which the $\mathrm{EV}$ is stationary at the Satellite buildings, the EVBs possibly discharge their stored electricity for the user needs. The EV velocity during the two equal trips ranges from 10 to $35 \mathrm{~km} / \mathrm{h}$.

The EVB discharge power is calculated according to the EV mobility routes and velocities [89], following the power consumption profile reported in Figure 2. For each $\mathrm{EV}$, the battery pack includes 6831 cells (18650 form factor Li-Ion battery, following an 11S 9S 69P configuration, (TeslaMotors, 2017)), with a capacity of about $60 \mathrm{kWh}$. At last, charger nominal power (from Grid) is $7.0 \mathrm{~kW}$ and the minimum and maximum SOC of each EVB are set to 30 and $90 \%$ of their nominal capacity.

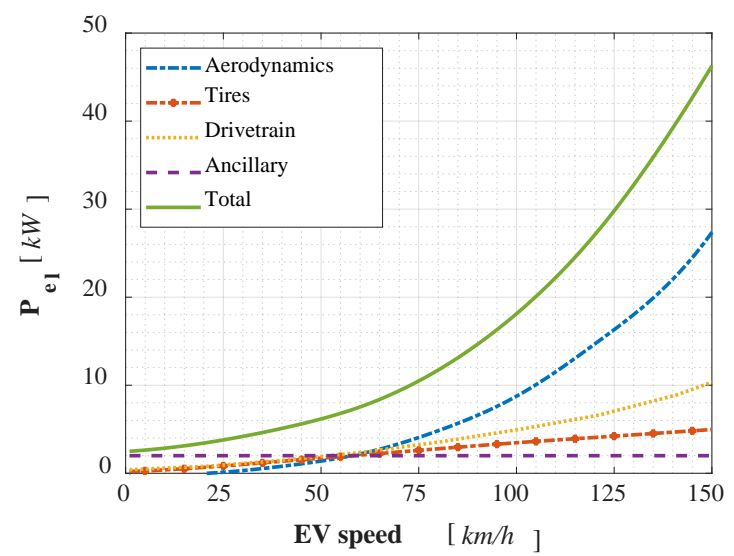

Figure 2. EV power consumption vs. driving speed (TeslaMotors, 2017).

The BIPV field (gross area of about $150 \mathrm{~m}^{2}$ ) is made of mono-crystalline silicon panels (electric efficiency of about $19 \%$ ), installed on the South oriented $30^{\circ}$ tilted roof of the Main building. The field PV peak power is $20 \mathrm{~kW}$.

Finally, simulations are carried out by using the Meteonorm hourly weather data file of Naples (Italy), having an index of incident solar radiation equal to 1529 $\mathrm{kWh} / \mathrm{m}^{2} \mathrm{y}$ and heating and cooling degree days of 1163 and $185 \mathrm{Kd}$, respectively. Yearly simulations run with a time step of 6 minutes.

\section{Result and discussion}

Simulation results obtained for the investigated case study are discussed hereinafter with the aim to assess the performance of the proposed $\mathrm{V}^{2} \mathrm{~B}^{2}$ concept applied to this office based virtual micro-grid.

Figure 3 shows the dynamic yearly profiles of the electricity needs (due to appliances, heating and cooling) of the main building. Similar profiles, not reported for the sake of brevity, are considered for the two satellite 
buildings. For all the buildings, the simulated electricity peak loads for heating are higher than the cooling ones. The yearly electricity demand of the Main user (nearly zero energy building) is about $44 \mathrm{kWh} / \mathrm{m}^{2}$ (about 14 $\mathrm{MWh}$ /year), whereas each Satellite one requires about 70 $\mathrm{kWh} / \mathrm{m}^{2}$ (about $13 \mathrm{MWh} /$ year) of electricity.

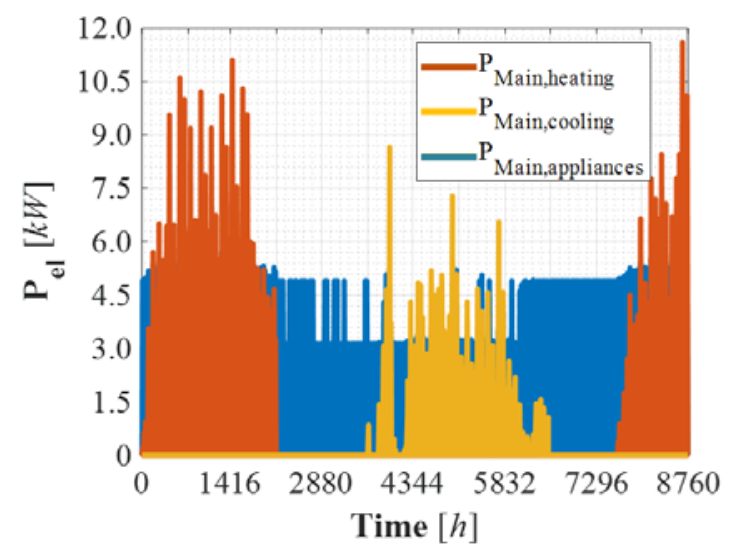

Figure 3. Main building electrical yearly demand.

The yearly electricity consumption of all the three EVs is about 7.8 MWh/year. The EVs electricity need corresponds to about $16.5 \%$ of the whole system energy demand, equal to about 47.3 $\mathrm{MWh} /$ year, whereas the renewable electricity production from $\mathrm{PV}$ panels is about 31.8 MWh/year, as shown in Figure 4.

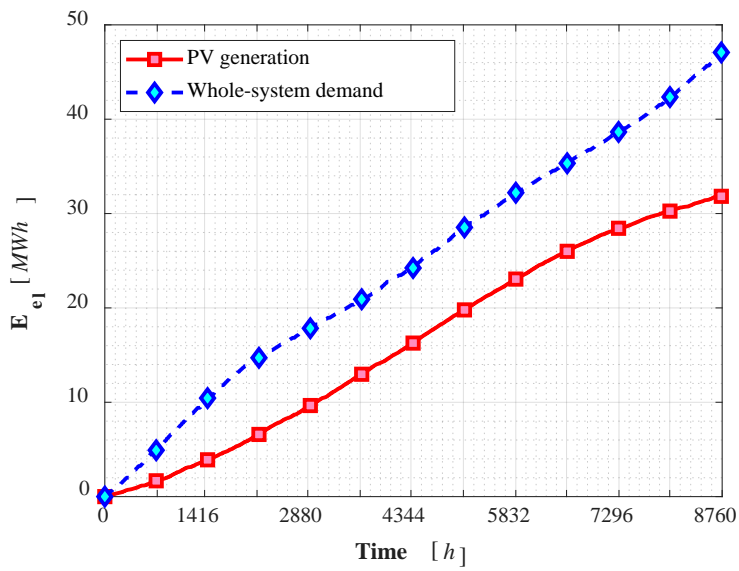

Figure 4. Annual electricity production and load profiles of the investigated system.

The yearly electricity production is lower than the electricity need of the whole system consisting of the three buildings (Main, Sat A, and Sat B) and of the three EVs (namely EV1, EV2 and EV3). Therefore, it is interesting to find out how the $\mathrm{V}_{2} \mathrm{~B}^{2}$ system management logic is able to increase the time-matching between load and PV production, maximizing the self-consumption of PV electricity, and thus reducing the Grid interaction.

In order to understand the performance of the investigated system layout, it is useful to assess the time histories of the key electricity flows. Figure 5 shows, for two sample winter days (sunny and cloudy), the electricity flows among the Grid, the EVBs, and the investigated buildings (Main building, Sat A, and Sat B). The selected sample days are February $12^{\text {th }}$ and $13^{\text {th }}$. In particular, the first graph (Figure 5, left) shows:

- $\quad$ PV generation power $\left(\mathrm{P}_{\mathrm{PV}}\right)$;

- Main building electricity load ( $\left.\mathrm{P}_{\text {Load Main }}\right)$;

- electricity energy supplied by the Grid and by the EV to the Main building ( $\mathrm{E}_{\mathrm{Grid}} \rightarrow$ Main and $\mathrm{E}_{\mathrm{EV}} \rightarrow$ Main $)$;

- exported renewable electricity (EPV $\rightarrow$ Grid, surplus).

The second and third graphs (Figure 5, middle and right), relative to Sat $\mathrm{A}$ and $\mathrm{Sat} \mathrm{B}$, show:

- Satellite users electricity load ( $\mathrm{P}_{\text {Load SatA }}$ and $\left.\mathrm{P}_{\text {Load Sat } \mathrm{B}}\right)$;

- electricity energy from the Grid and from the EV to each Satellite building, i.e. for Sat $A\left(E_{G r i d} \rightarrow\right.$ Sat $A$ and $\left.\mathrm{E}_{\mathrm{EV} \rightarrow \text { Sat }} \mathrm{A}\right)$, for Sat B $\left(\mathrm{E}_{\mathrm{Grid}} \rightarrow\right.$ Sat B and $\left.\mathrm{E}_{\mathrm{EV} \rightarrow \text { Sat B }}\right)$.

Note that, the three EVs have different routes, and every day they follow the daily stay, morning stay, and leave strategies according to their SOC level (as previously discussed).

At the beginning of the first day, the Main building load is higher than the PV production (low solar radiation), so the $\mathrm{P}_{\text {Load Main }}$ is balanced through the electricity supplied by the EV plugged to the building BMS. When the EVs leave the building (or the SOC of the plugged EVs are lower than the minimum level), $\mathrm{P}_{\text {Load Main }}$ is balanced by the Grid. When the sun rises and the PV generation is higher than the building load $\left(\mathrm{P}_{\mathrm{PV}}>\mathrm{P}_{\mathrm{Load} \text { Main }}\right), \mathrm{P}_{\mathrm{Load} \text { Main }}$ is completely balanced by $\mathrm{P}_{\mathrm{PV}}$ and the production surplus is firstly delivered to the EVs plugged to the BMS and subsequently to the Grid. At early evening, when the solar radiation decreases, the building load becomes again higher than the PV generation, so electricity from the EV is delivered to the Main building user $\left(\mathrm{E}_{\mathrm{EV} \rightarrow \text { Main }}\right)$, reducing its SOC. During the same day (February $12^{\text {th }}$ ), a significant part of the Satellites users loads ( $\mathrm{P}_{\text {Load Sat A }}$ and $\mathrm{P}_{\text {Load Sat } \mathrm{B}}$ ) is balanced by the electricity supplied by the EVs reaching these buildings. The dispatched electricity depends on the amount of time in which the EVs are plugged to the Satellite buildings, as well as on their SOC. From such figures (Figure 5, middle and right), it is clearly notable that the ratio of renewable electricity exploited off-site is highly dependent on the EVs routes and schedules, suggesting more research in this field (i.e. stochastic modelling of electric vehicles use, urban planning and programming of vehicle to building interactions, etc.). The second day displayed in Figure 5 (February $13^{\text {th }}$, cloudy day), clearly shows that with low solar radiation, $\mathrm{P}_{\mathrm{PV}}>\mathrm{P}_{\text {Load Main }}$, the Grid supplies most of the electricity need to the Main building, as well as to the Satellite users, Sat A and Sat B. Insufficient PV generation also causes a significant reduction of renewable electricity dispatched to the Satellite buildings. In fact, only Sat $\mathrm{A}$ is supplied with $\mathrm{P}_{\mathrm{PV}}$, whereas no PV generation is dispatched to Sat B. 

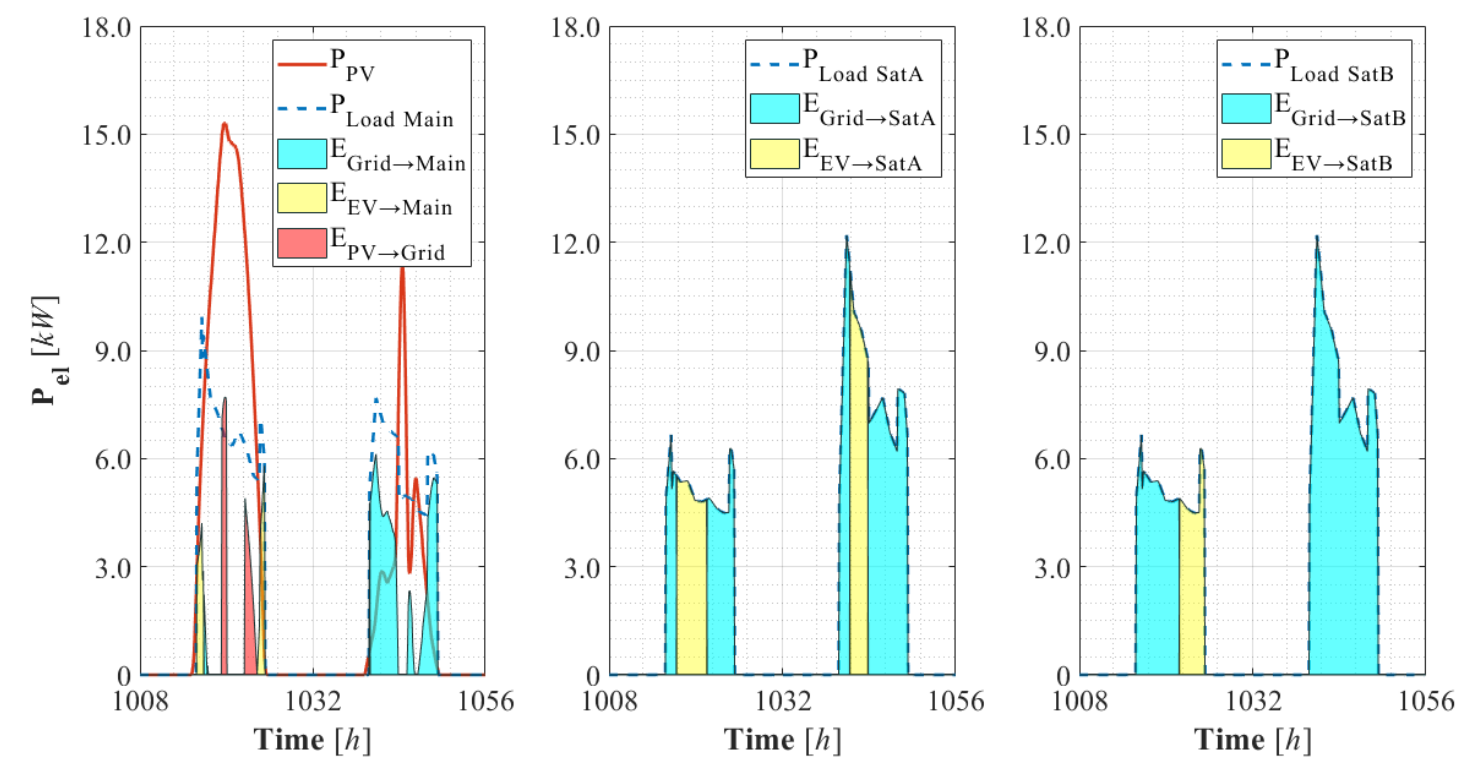

Figure 5. Dynamic profiles of electrical flows from Grid and EVs to Main bldg., Sat A, and Sat B $-\mathrm{Feb} .12^{\text {th }}$ and $13^{\text {th }}$.

In order to better show how each EV interacts with the users of the considered virtual micro-grid, Figure 6 shows the dynamic profiles of:

- EV motion (time scheduling, $\mathrm{EV}_{\text {motion }}$ );

- electricity provided by the Grid and by the EV ( $E_{G r i d}$ $\rightarrow$ Main and $\mathrm{E}_{\mathrm{EV} \rightarrow \text { Main }}$;

- users' loads ( $\mathrm{P}_{\text {Load Main, }} \mathrm{P}_{\text {Load Sat }} \mathrm{A}$, and $\mathrm{P}_{\text {Load Sat } \mathrm{B} \text {, }}$ respectively, in Figure 6, left, middle, right);

- $\quad \mathrm{PV}$ generation power $\left(\mathrm{P}_{\mathrm{PV}}\right)$;

- SOC levels of the three EVs.

The time histories of Figure 6 refer to two sample spring days, May $19^{\text {th }}$ and $20^{\text {th }}$, respectively, where electricity is only due to appliances (which have the same schedules, thus profiles, for all buildings). These days refer to Saturday (offices open) and to Sunday (offices closed), with the aim to better show how EVBs are charged. The EV with the lowest charge of the battery (EV1) remains plugged to the BMS of the Main building (Figure 6, left), following the daily stay pattern strategy, so that it can be charged with $\mathrm{P}_{\mathrm{PV}}$. According to such schedule, the EV leaves for two short trips (highlighted with the green EV motion bars), scheduled between 9:00 am and 9:35 am and between 11:30 am and 12:10 pm. In the first day (working day), when the EV is plugged to the Main building, $\mathrm{PV}$ generation is practically always higher than the user demand $\left(\mathrm{P}_{\mathrm{PV}}>\mathrm{P}_{\text {Load Main }}\right)$, so the EVB is charged with the surplus of renewable power production, and its SOC level increases. According the EV motion scheduling, the battery of the EV1 is discharged (note that the slope of the SOC profile depends on the motion velocity). The EV1 remains plugged to the BMS of the Main building from 12:10 pm, so the EVB is charged until its SOC reaches the maximum level, set at 0.9 , achieved at the end of the first displayed day. The second vehicle, EV2, with the second highest SOC level, follows the morning stay schedule. According to such schedule, EV2 remains plugged to the Main building BMS during the morning. When EV1 is in motion (from 9:00 am to 9:35 am), the surplus of PV generation is supplied to the EV2 battery, increasing its SOC level. At 1:00 pm EV2 leaves the Main building to reach one of the two Satellite ones (Sat A in Figure 6, middle), returning to the Main building at $6.30 \mathrm{pm}$. Thus, EV2 needs electricity for its motion and it also balances, for a small fraction of time, part of the Sat A electricity demand (until the minimum SOC level, equal to 0.3). The same considerations can be applied to EV3, which reaches Sat $\mathrm{B}$ by following the leave schedule, being the vehicle at the highest possible SOC level. Therefore, EV3 leaves the Main building to reach Sat B where it remains from 9:20 am to 5:30 pm. At Sat $\mathrm{B}$, the SOC level of the EV3 battery decreases during the time by supplying off-site renewable electricity to the user. Once the minimum SOC level is reached, the Grid (operating as a back-up system) provides the extra energy need. A further decrease of the SOC level is obviously due to the motion of EV3 returning to the Main building. At the beginning of the second day (Sunday, closed offices), when all EVs are all day long connected to the BMS of the Main building, the first EVB to be supplied through the solar radiation (always in surplus, being null the buildings electricity demand), is the one with the highest SOC level (i.e. EV1). When this battery becomes full (the maximum SOC of 0.9 is reached), the subsequent EVB to be supplied by PV electricity is the EV3 one, see Figure 6, right. Similarly, when EV3 is full (it reaches $0.9), P_{P V}$ feeds the EV2 battery until its maximum SOC level is achieved. Surplus of PV generation is, thus, exported to the Grid.

The proposed ${\mathrm{V} 2 \mathrm{~B}^{2}}^{2}$ strategy causes a reduction of electricity supply by the Grid and the enhancement of the matching between generation and demand. If compared to the reference system (RS, where the off-site dispatchment of the Main building PV production to the Satellite ones is not obtained), a significant reduction of PV production exported to the Grid is observed. 

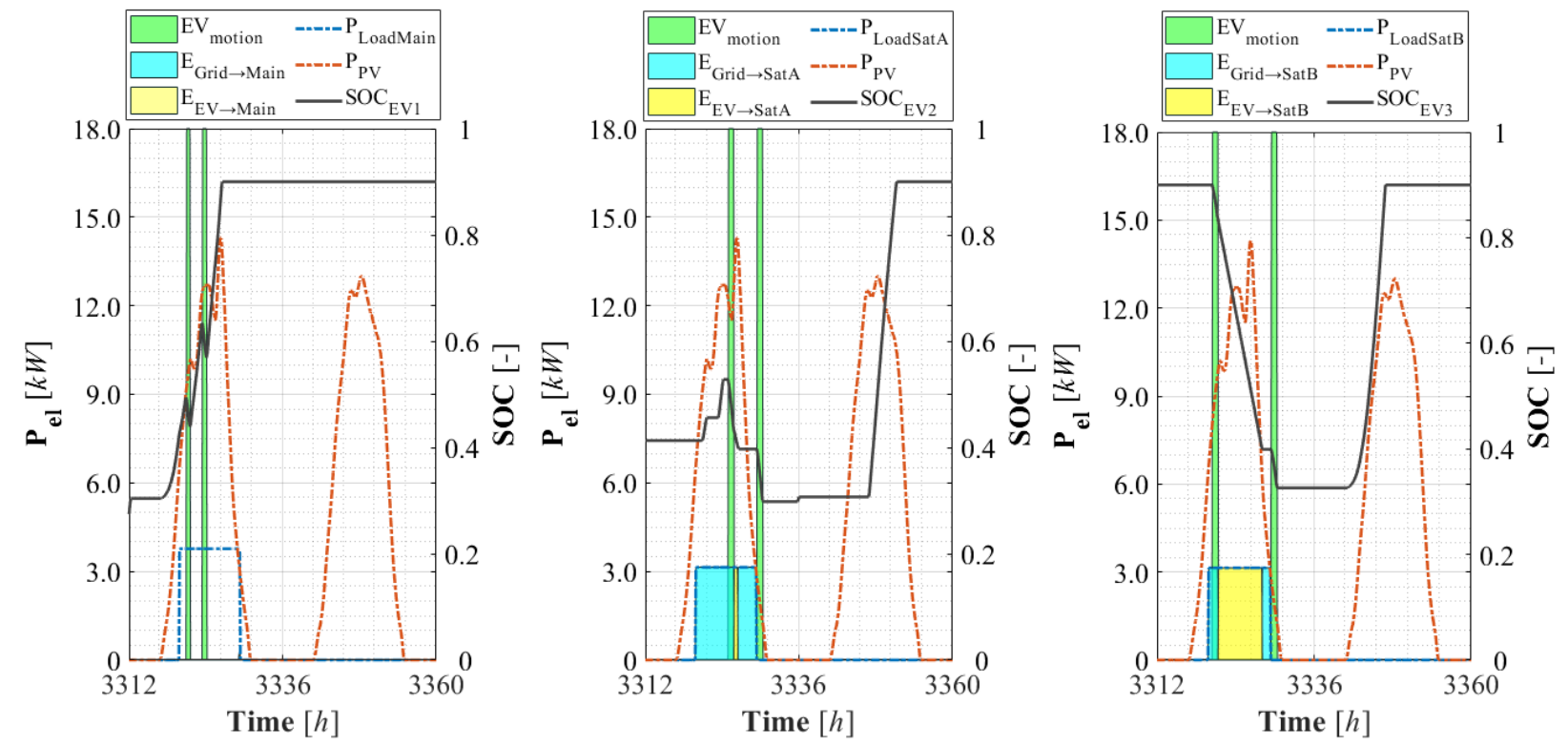

Figure 6. Dynamic profiles of users loads, PV generation and SOC levels, together with EV motion schedules - May $19^{\text {th }}$ and $20^{\text {th }}$.

The amount of electricity produced by PV panels and selfconsumed by the users of the considered micro-grid (Main building, Sat A, Sat B, and EVs) is shown in Figure 7 , on a monthly basis, for both the reference and proposed systems (RS and PS, respectively).

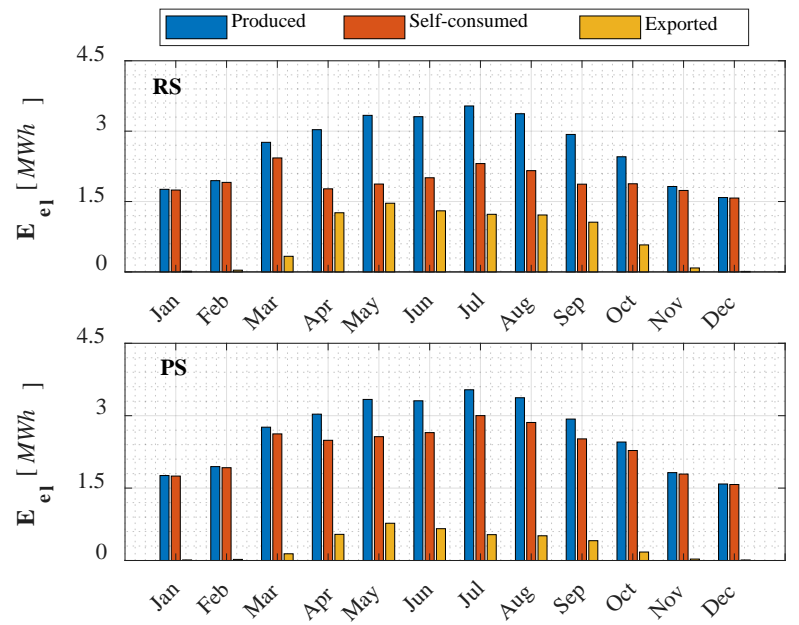

Figure 7. Monthly renewable energy produced by $P V$, self-consumed (by Main building, Sat A, Sat B, and EVs) and exported to Grid.

This figure clearly shows that, by comparing the RS to the PS layout, a remarkable amount of electricity exported (in the RS) is self-consumed (in the PS), especially in summer months. During winter months, there is no exported electricity by both layouts, since the amount of PV production is almost completely self-consumed. It is worth noting that, the PS system implies a higher amount of losses, due to the increase of EVB charging and discharging cycles, compared to those of the RS system (where a reduced number of charge and discharge cycles occur). Nevertheless, although such higher electricity losses, by the PS layouts an increase of self-consumed electricity (corresponding to a decrease of the electricity sold to the Grid) is obtained. Such occurrence, in addition to mitigate the renewable electricity impact/issues on the Grid, provides a better economic result with respect to RS, as discussed hereinafter.

On the yearly basis, the shift from exported to selfconsumed electricity, passing from the RS to the PS layout, is shown in Figure 8. For a produced PV electricity of about $31.9 \mathrm{MWh} / \mathrm{y}$, the following results are obtained:

- for the RS layout, 23.3 MWh/y is self-consumed, and 8.58 MWh/y is exported;

- for the PS layout, 28.0 MWh/y is self-consumed (by Satellite buildings too), and 3.82 MWh/y is exported.

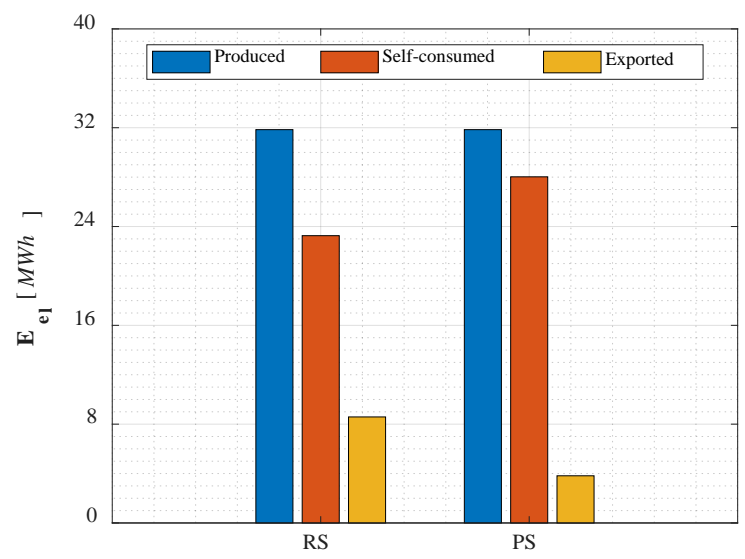

Figure 8. Yearly PV electricity, self-consumed (by Main bldg., Sat A, Sat B, and EVs) and exported to Grid.

The overall performance of the PS and RS layouts (i.e. $\mathrm{V}^{2} \mathrm{~B}^{2}$ vs. V2B) are compared in Figure 9, which shows the cumulative generation, imported and exported electricity profiles. The best exploitation of the RES is achieved by the PS layout, with the lowest imported 
electricity, leading to a remarkable reduction of the electricity exported to the Grid. The difference between PS and RS performances rises mostly after April, due to the increase of PV generation, as shown in Figure 7.

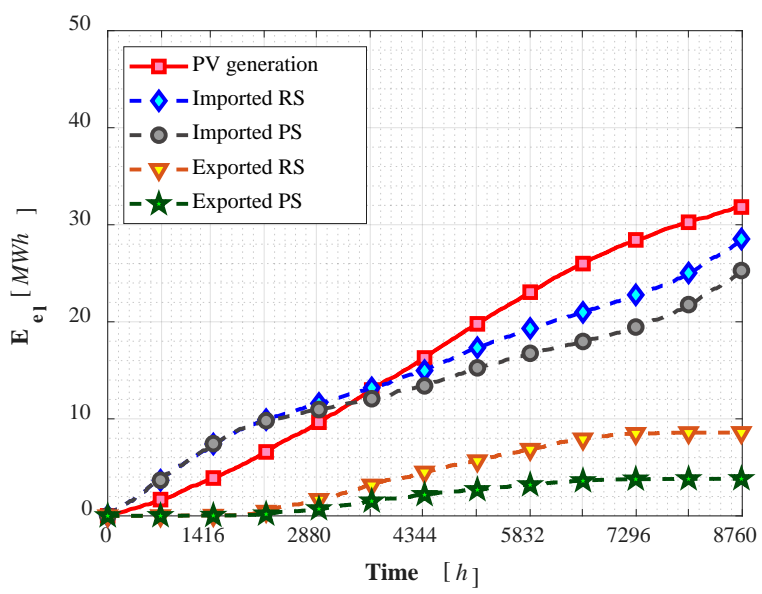

Figure 9. Cumulative delivered and exported electricity to and from the investigated system.

Nevertheless, with respect to the typical V2B scenario (RS layout), the V2B ${ }^{2}$ one (PS layout) shows a lower reduction of electricity delivered from the Grid with respect to the exported one. Thus, a better economic performance is observed due to the difference between purchase and feed-in tariffs, which highly advantage the PS scenario. The imported electricity is purchased from the Grid at the average price of $0.20 € / \mathrm{kWh}$, where the exported one is sold at a time-dependent feed-in tariff, known as hourly National Single Price, NSP (Barone et al., 2019), which is averagely lower than $0.09 € / \mathrm{kWh}$.

Yearly energy and economic performance of both scenarios are reported in Table 2. The difference between delivered and exported electricity, about 20.1 MWh/y for RS and 21.6 MWh/y for PS, suggests that the proposed scenario is economically feasible if the feed-in tariff is lower than the purchase price. In fact, increasing the selfconsumed electricity (i.e. reducing the sold one), at the expense of the exported amount, produces an economic saving of about $8.1 \%$. It is also worth noticing that the PS scenario versus the RS one does not require to buy expensive technical equipment, and thus considering any significant investment. Besides the economic performance, it is also interesting to note the fossil energy saving, about $11.4 \%$, obtained by simply managing the use of EVs in the considered micro-grid.

It is worth noticing that the proposed scenario influences the energy performance of each user of the considered virtual micro-grid system. To this aim, Table 3 reports the yearly electricity needs, and the amount of fossil and renewable self-consumed electricity, required by each user of the considered micro-grid. Passing from the RS to the PS scenario, the fossil electricity demands of the Main building and EVs increase (+0.19 and +1.64 MWh/y, respectively), whereas those of Sat A and Sat B (in total $5.1 \mathrm{MWh} / \mathrm{y}$ ) decrease. Therefore, the ${\mathrm{V} 2 \mathrm{~B}^{2}}^{2}$ scenario is effectively able to enhance the micro-grid performance, by dispatching electricity among its users. This also allows one to promote, at a micro-grid level, the energy efficiency of buildings, which may approach the nearly Zero Energy Building (nZEB) target (i.e. final electricity demand $<50 \mathrm{kWh} / \mathrm{m}^{2} \mathrm{y}$ ) without refurbishments and/or installations of on-site RES technologies.

Table 2. Energy and economic indexes.

\begin{tabular}{|c|c|c|}
\hline Electric energy indexes & $\begin{array}{c}\text { RS } \\
\text { (V2B) }\end{array}$ & $\begin{array}{c}\text { PS } \\
\text { (V2B }\end{array}$ \\
\hline PV production $[M W h]$ & \multicolumn{2}{|c|}{31.9} \\
\hline Grid fossil demand $[M W h]$ & 28.6 & 25.4 \\
\hline RES Self consumption [MWh] & 23.3 & 28.0 \\
\hline Fossil energy saving [\%] & - & 11.4 \\
\hline RES Exported [MWh] & 8.58 & 3.82 \\
\hline Delivered minus Exported [MWh] & 20.1 & 21.6 \\
\hline Percentage losses [\%] & - & 11.3 \\
\hline Economic Indexes & & \\
\hline Purchased electricity [k€] & 5.72 & 5.08 \\
\hline Sold electricity [k€] & 0.386 & 0.167 \\
\hline Purchased - Sold [k€] & 5.34 & 4.91 \\
\hline Percentage saving [\%] & - & 8.06 \\
\hline
\end{tabular}

Table 3. Yearly electricity demand, consumption fossil and renewable electricity of each user.

\begin{tabular}{|c|c|c|c|}
\hline Electricity $[M W h / y]$ & $\begin{array}{c}\text { Main } \\
\text { building }\end{array}$ & $\begin{array}{c}\text { Sat A + } \\
\text { Sat B }\end{array}$ & EVs \\
\hline Demand & 13.5 & \multirow{2}{*}{26.0} & 7.75 \\
\cline { 5 - 5 } & 1.62 & & 1.05 \\
\hline RS fossil consumption & 1.81 & 20.9 & 2.69 \\
\hline PS fossil consumption & 11.9 & - & 6.70 \\
\hline RS RES self-consumption & 11.7 & 5.07 & 5.06 \\
\hline PS RES self-consumption & \multicolumn{3}{|c}{}
\end{tabular}

This is clearly highlighted in Table 4, where the building energy performance, in terms of final electricity demand for square meter, is reported for the Main and Satellite buildings and for all investigated scenarios. The electricity demand of the whole cluster of buildings (i.e. Main, Sat A and Sat B), without considering any on-site RES (No RES, Table 4), is equal to $58.0 \mathrm{kWh} / \mathrm{m}^{2} \mathrm{y}$ (45.0 $\mathrm{kWh} / \mathrm{m}^{2} \mathrm{y}$ for the Main building, already an $\mathrm{nZEB}$, and $68.4 \mathrm{kWh} / \mathrm{m}^{2} \mathrm{y}$ for Sat A and Sat B).

Table 4. Building energy performance.

\begin{tabular}{|c|c|c|}
\hline \multirow{2}{*}{$\begin{array}{c}\text { Building final electric } \\
\text { (fossil) demand }\left[\mathrm{kWh} / \mathrm{m}^{2} \mathrm{y}\right]\end{array}$} & Main bldg. & Sat A-B \\
\hline & \multicolumn{2}{|c|}{ (Main bldg. + Sat A + Sat B) } \\
\hline \multirow{2}{*}{ No RES } & 45.0 & 68.4 \\
\hline & \multicolumn{2}{|c|}{$(58.0)$} \\
\hline \multirow{2}{*}{ RS demand } & 5.40 & 68.4 \\
\hline & \multicolumn{2}{|c|}{$(40.6)$} \\
\hline \multirow{2}{*}{ PS demand } & 6.03 & 55.0 \\
\hline & \multicolumn{2}{|c|}{$(33.4)$} \\
\hline
\end{tabular}

The installation of RES technologies and the utilization of the EVs of the micro-grid as energy source and sink of the Main building only (bidirectional operation), i.e. RS layout or V2B scenario, highly reduce the final electrical demand of the whole cluster of buildings, down to 40.6 $\mathrm{kWh} / \mathrm{m}^{2} \mathrm{y}$. This result is only due to the exploitation of PV 
production at the Main building level (use of on-site RES produced electricity), passing from $45.0 \mathrm{kWh} / \mathrm{m}^{2} \mathrm{y}$ to 5.40 $\mathrm{kWh} / \mathrm{m}^{2} \mathrm{y}$. Finally, the PS layout (V2B ${ }^{2}$ scenario) reduced the final demand of such cluster of buildings down to 33.4 $\mathrm{kWh} / \mathrm{m}^{2} \mathrm{y}$, by basically lowering the Satellite building demand of about $19.6 \%$, from $68.4 \mathrm{kWh} / \mathrm{m}^{2} \mathrm{y}$ to 55.0 $\mathrm{kWh} / \mathrm{m}^{2} \mathrm{y}$ (approaching the nZEB target).

Although the discussed results are linked to the specific case study, they are remarkably encouraging for smart grid applications necessary to promote the sustainable energy transition of cities and urban centres, as well as toward the achievement of energy-self-sufficient communities of remote areas. Further analyses and optimizations will be carried out, by considering different scenarios, strategies, and stochastic users' profiles (building demands, RES and storage capacities, EV patterns, as well as weather forecast).

\section{Nomenclature}

$\begin{array}{ll}\text { BIPV } & \text { Building Integrated PhotoVoltaic } \\ \text { BMS } & \text { Building Management System } \\ \text { EV } & \text { Electric Vehicle } \\ \text { EVB } & \text { Electric Vehicle Battery } \\ \text { Grid } & \text { Power grid } \\ \text { Main } & \text { Main building, with on-site RES } \\ \text { nZEB } & \text { nearly Zero Energy Building } \\ \text { P } & \text { Power [kW] } \\ \text { PS } & \text { Proposed System } \\ \text { RS } & \text { Reference System } \\ \text { PV } & \text { Photovoltaic } \\ \text { RES } & \text { Renewable Energy Sources } \\ \text { Sat } & \text { Satellite building, without on-site RES } \\ \text { SOC } & \text { State Of Charge [-] } \\ \text { V2B } & \text { Building to Vehicle to Building } \\ \text { V2B } & \text { Vehicle to Building }\end{array}$

\section{Conclusion}

In this paper, a novel energy management scheme for grid-connected buildings and electric vehicles, namely Building to Vehicle to Building (V2B ${ }^{2}$ ) is presented and analysed. This concept aims to promote the achievement of the net or nearly zero energy building (NZEB or nZEB) target at micro-grid scale level, by exploiting the use of off-site PV production dispatched by electric vehicles (EVs). EVs are considered as storage devices and energy vectors among multiple buildings included within a virtual cluster of buildings. To assess the whole system energy and economic performance, a suitable dynamic simulation tool is developed in TRNSYS environment.

To show the potentials of the proposed V2 ${ }^{2}$ concept, as well as the capabilities of the tool, a case study analysis is presented. Such study refers to a micro-grid consisting of 3 office buildings (with roof-integrated PV panels, located on-site on the main building only) and 3 electric vehicles, which rotates/commutes from one building to another, dispatching RES stored electricity with the aim of enhancing the exploitation of PV production.
Simulation results are compared to those achieved for the same cluster of buildings where the electric vehicles are only plugged to the main building with on-site RES, exchanging electricity with it and the grid.

Simulation results show that the use of electric vehicle as energy vectors at micro-grid scale can effectively benefit the whole systems in terms of reduction of fossil electricity consumptions, by increasing the selfconsumption of renewable energy. The simulated microgrid showed interesting energy and economic results, e.g. fossil electricity saving of about $11.4 \%$ and economic saving of 8.1\%. In addition, by exploiting the off-site PV production, the nZEB target can be approached at microgrid scale. The electricity demand of Satellite buildings (exploiting off-site PV production, dispatched by the EVs) is effectively reduced (of about $20 \%$ ) without any refurbishment or relevant new devices installation. The economic convenience, highly influenced by the national electricity prices, shows that suitable energy policies are necessary to promote the adoption of such systems and concept. Future investigations, including parametric and optimization analyses, will be conducted through the developed model, by also considering different case study scenarios and stochastic users' profiles.

\section{References}

Barone, G., Buonomano, A., Calise, F., Forzano, C., \& Palombo, A. (2019). Building to vehicle to building concept toward a novel zero energy paradigm: Modelling and case studies. Renewable and Sustainable Energy Reviews, 101, 625-648.

Buonomano A. (2020). Building to Vehicle to Building concept: A comprehensive parametric and sensitivity analysis for decision making aims. Applied Energy, 261, 114077.

Damiano A., Gatto G., Marongiu I., Porru M., \& A., S. (2014). Real-Time Control Strategy of Energy Storage Systems for Renewable Energy Sources Exploitation. IEEE Transactions on Sust. Energy, 5(2), 567-576.

De Angelis F., Boaro M., Fuselli D., Squartini S., Piazza F., \& Q., W. (2013). Optimal Home Energy Management Under Dynamic Electrical and Thermal Constraints. IEEE Transactions on Industrial Informatics, 9(3), 1518-1527.

Klein S.A., Beckman W.A., Mitchell J.W., Duffie J.A., \& Duffie N.A. (2006). Solar energy laboratory, TRNSYS. A transient system simulation program.

Kuang Y., Hu M., Dai R., \& D., Y. (2017). A Collaborative Decision Model for Electric Vehicle to Building Integration. Energy Procedia, 105(Supplement C), 2077-2082.

Salpakari J., Rasku T., Lindgren J., \& P.D., L. (2017). Flexibility of electric vehicles and space heating in net zero energy houses: an optimal control model with thermal dynamics and battery degradation. Applied Energy, 190(Supplement C), 800-812.

TeslaMotors. (2017). Tesla Roadster Features and Specifications (tesla.com/destination-charging) 